\title{
Cloud-to-Ground Lightning Characteristics of the Tornadic Storm over Hokkaido on November 7, 2006
}

\author{
Fumiaki Kobayashi ${ }^{1}$ and Yuya Sugawara ${ }^{1}$ \\ ${ }^{1}$ Department of Geoscience, National Defense Academy, Yokosuka, 239-8686, Japan
}

\begin{abstract}
The relationship between the evolution of the tornadic storm and the cloud-to-ground (CG) activity was investigated on the F3 tornado event in Saroma-cho, Hokkaido on 7 November 2006. The echo system which caused tornadoes in Saroma-cho was the mesoscale convective system (MCS) having both the convective core region and the stratiform region. CG lightning was active in the decaying stage of the MCS. Most CG lightning was negative and occurred around a relatively strong echo area in the stratiform region of the MCS. The MCS had two peaks of the CG lightning activity at the developing and decaying stages. The Saroma tornado occurred at the decaying stage of the system when the concentration of CG frequency was observed.
\end{abstract}

Key words : CG lightning, tornado, mesoscale convective system

\section{Introduction}

F3 (Fujita scale; Fujita, 1981) tornado occurred in Saroma-cho, Hokkaido on 7 November 2006, which resulted in 9 deaths. The "Saroma tornado" was one of the most serious tornado events in Japan. F3 tornadoes (F3 tornado rank: 70-92 m/s estimated wind speed) have been reported at Mobara-city, Chiba prefecture on 11 December 1990 and at Toyohashi-city, Aichi prefecture on 24 September 1999. According to the statistical study, F3 tornado occurred about once per 10 years (Kobayashi, 2007). About 25 tornadoes per year in average occurred during recent 10 years in Japan. $40 \%$ of tornadoes are associated with extratropical cyclones and observed in all year round. The peak of frequency appears during September (typhoon season) to November (early winter season).

Lightning evolution in tornadic storms has been discussed in the USA. Some patterns were reported in the relationship between tornado generation and ground flash rate. Ground flash rate peaked during tornadoes (e.g., MacGorman and Nielsen, 1991), but in other cases, the peak of ground flash rate was observed before (e.g., Orville et al., 1982) and after (e.g., Kane, 1991) tornadoes. Also, the studies of lightning characteristics in the mesoscale convective system (MCS) have been reported (e.g., Rutledge and MacGorman, 1988, Rutledge et al., 1990). The features of ground flashes in MCSs are followings : (1) negative ground flash rates tend to increase during MCS initiation. (2) Negative ground flashes in MCSs are associated with the deep convection. (3) Positive ground flashes begin to occur within the stratiform region of MCSs. 
In Japan, supercell tornadoes accompanying mesocyclones in the parent cloud have been reported (e.g., Niino et al., 1993; Kobayashi et al., 1996). While non-supercell tornadoes and waterspouts have been observed together with a variety of weather conditions including extratropical cyclones, winter monsoon and upper-level cold air (e.g., Kobayashi et al., 2007a, 2007b, Sugawara and Kobayashi, 2008), there are a few cases where the tornado generated in the MCS has been observed extensively. Moreover, the structures of CG (cloud-to-ground) lightning in the supercell/ non-supercell thunderstorms remain uncertain. In this paper, the relationship between the evolution of the tornadic storm and the CG activity of the Saroma tornado using the routine observational data of JMA (Japan Meteorological Agency) and CG lightning data obtained from LPATS (Lightning Position and Tracking System) and IMPACT (Improved Performance from Combined Technology) of Franklin Japan Corporation is discussed.

\section{Synoptic situations}

The surface weather chart at 12:00 JST (Japan Standard Time) on 7 November 2006 shows a cold front extending from the $996 \mathrm{hPa}$ low pressure system to Hokkaido and the main island of Japan (Fig. 1). The synoptic low pressure moved slowly towards the east as the cold front passed over Hokkaido. Convective clouds were observed along the cold front according to the geostationary meteorological satellite (GMS) MTSAT-1R visible image at 13:30 JST. Convection around this cold front was active and accompanied by a band of cumulonimbus clouds that had formed in the cold front. According to AMeDAS (Automated Meteorological Data Acquisition System) observations, surface temperature at Saroma was $18^{\circ} \mathrm{C}$ at 12:00 JST before the passage of the cold front. It is likely that the cold front had maintained the structure with a narrow temperature gradient. Cumulonimbus with a strong radar echo was generated in the frontal and pre-frontal area over Hokkaido. The strong radar echo corresponds to a precipitation intensity of over $40 \mathrm{~mm} / \mathrm{h}$. Some damage by the wind gust was reported in Hokkaido after 11:00 JST at the passage of the cold front.
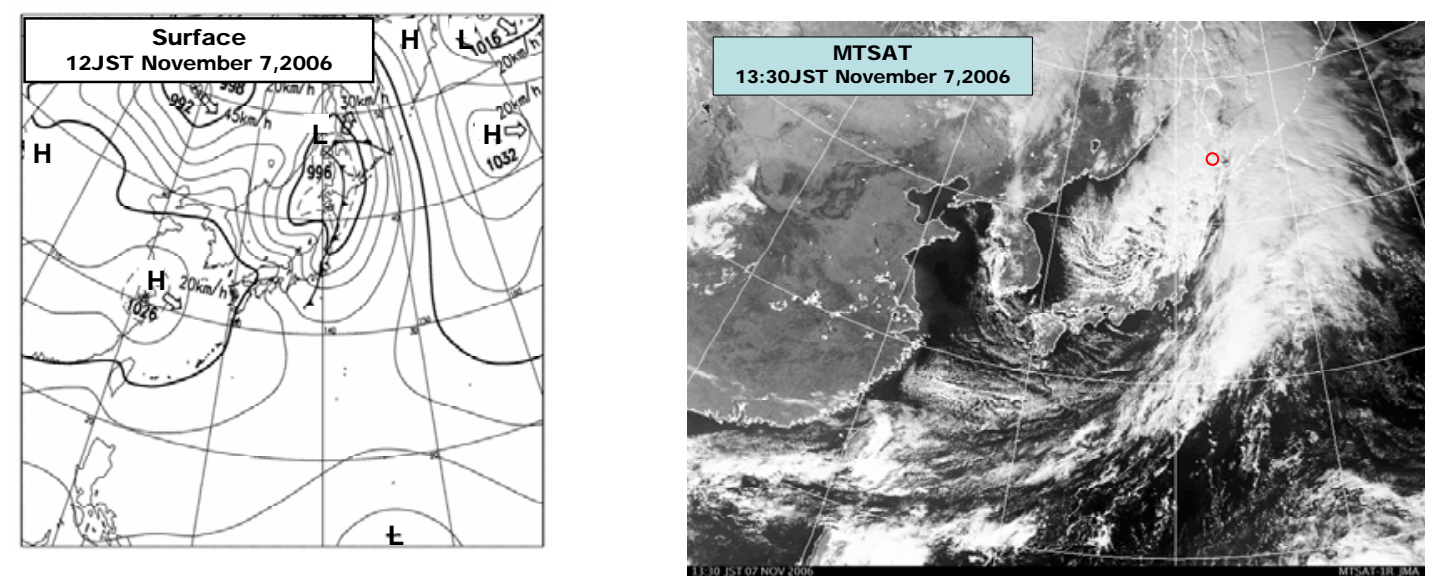

Fig. 1 Surface weather chart at 12:00 JST on 7 November 2006 (left) and GMS satellite visible image at 13:30 JST (right). Open circle denotes the location of Saroma-cho. 


\section{Surface damage in Saroma}

In Saroma-cho, at 13:23 JST on 7 November 2006, a strong gust of wind occurred that caused damage in Wakasa area of Saroma-cho. Figure 2 is a damage map drawn up after a 3-day field survey, which shows the locations of damaged residential houses, warehouses, temporary structures and trees that were completely or partly destroyed. Damage to over 30 residential houses was observed, with the affected area covering $1.5 \mathrm{~km}$ by $200 \mathrm{~m}$. The most severe damage occurred in almost a straight line (tornado path No. 1 in Fig. 2) on the right side of the tornado, because the moving speed of the tornado was high (about $20 \mathrm{~m} / \mathrm{s}$, see Table 1). Part of a temporary 2- storey building and a truck were blown 60-90 $\mathrm{m}$ at the south edge of the damage area (Fig. 3a). This damage feature corresponded to F3 (70-92 m/s) rank.

Distinct features of the damage included that: 1) the damage area was practically in a straight line, and 2) there were indications of cyclonic (rotary) winds, determined by tracing debris, flying debris and surveying surface damage patterns (Fig. 3b). These features suggested that the damage was caused by a tornado. East side of the tornado path No. 1 (Fig. 3c), and other tornado paths were observed (right figure in Fig. 2). This damage feature means that at least three suction vortices caused the damage. The overall damage rank was estimated to be F2-P1 (length)-P1 (width) on the Fujita-Pearson-scale (FPP-scale, see Tale 1). Overall affected area was $3 \mathrm{~km}$ by $1 \mathrm{~km}$ as shown in Fig. 2. Moreover, some materials were found on the Lake Saroma $20 \mathrm{~km}$ to the north, which means the existence of a long-lasting parent vortex (mesocyclone). There were many eyewitness accounts of the rotating clouds and funnel clouds because of the daytime event. Some pictures of "dust column" near the surface were taken for the analysis.
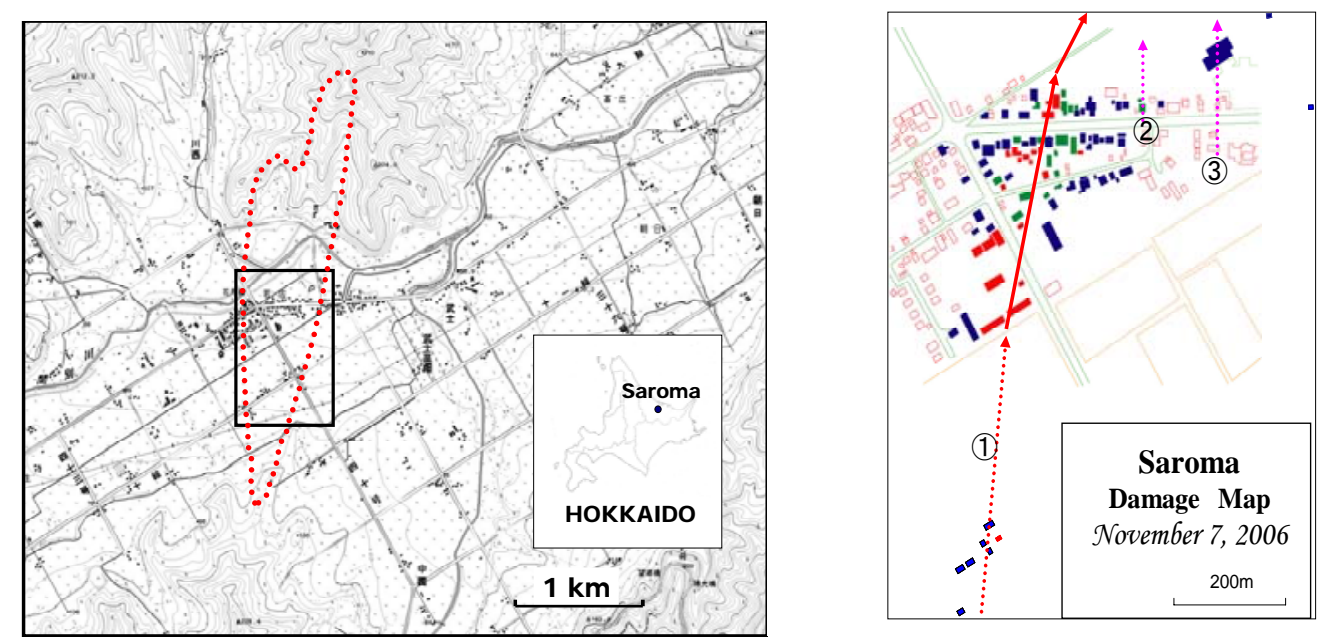

Fig. 2 Damage map of Saroma-cho. Dotted line (left) denotes the edge of the damage area. Arrows and solid rectangular blocks (right) denote tornado paths (from No.1 to No.3) and damaged houses, respectively. 


\section{CG distributions around the tornadic storm}

Figure 4 shows CG lightning distribution over Hokkaido from 11:00 to 14:00 JST on 7 November 2006. CG lightning was concentrated in the south to north direction along the frontal and prefrontal region. No lightning was observed around Saroma-cho before 13:00 JST. An active CG area was observed at the central region of Hokkaido and south and north side of Saroma-cho after 13:00 JST. The rate of CG frequency exceeded 1000 times per hour. This value means that the CG activity of this case was high like summer time thunderclouds. Generally, CG frequency is low in early winter in Hokkaido, because winter thunderclouds are dominant under the cold air outbreaks. Kobayashi (2006) reported another tornadic storm that occurred in Yamagata prefecture on 25 December 2005. The thundercloud developed at the landing in the pre-front area of the developing low pressure system and several times of the CG lightning were observed.
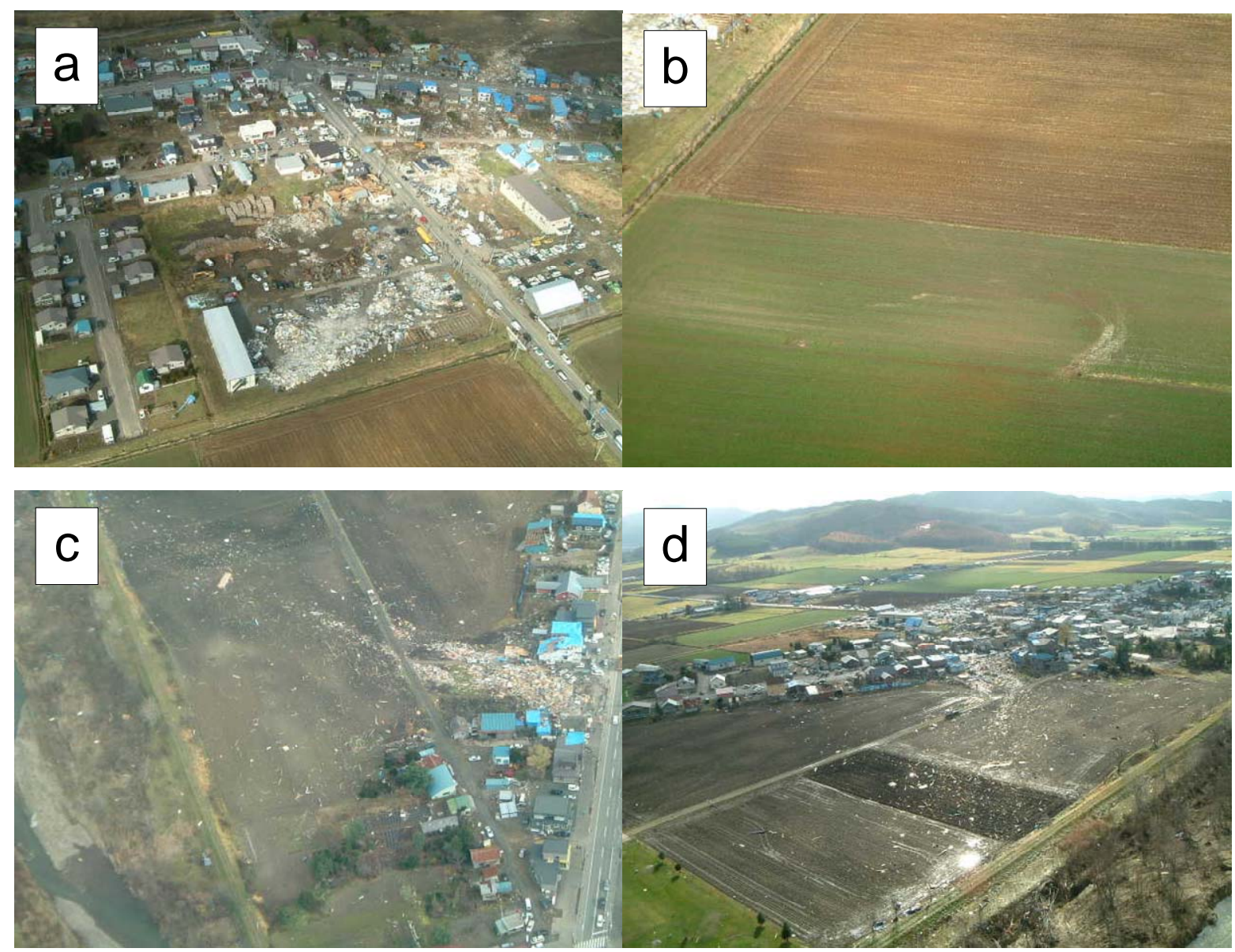

Fig. 3 Photos of the damage. (a) Overview of the damage looking toward the north. (b) The tornadic trace on the ground surface at the south edge of the damage. The diameter of the cyclonic trace was approximately $30 \mathrm{~m}$. (c) The completely destroyed house and the distribution of flying debris at the north part of the town. (d) Overview of the damage looking toward the southwest. (photos by F. Kobayashi) 
Figure 5 shows the temporal change of the radar echo from 11:00 to 14:00 JST. The radar echo system was generated over the sea and landed at 11:00 JST. This echo system moved to NNE direction at the speed of $70 \mathrm{~km} / \mathrm{h}$. The echo area, which was at the radar intensity larger than $1 \mathrm{~mm} / \mathrm{h}$, spread gradually and the strong echo core region of the radar intensity larger than $40 \mathrm{~mm} / \mathrm{h}$ was observed during the whole lifetime of the system (more than 3 hours). Figure 6 shows the radar echo images during (13:20 JST) and after (13:30 JST) the tornado generation superimposed by CG lightning distribution (+ and - marks) within the echo system (rectangular region). The echo system had the convective core region at the south edge of the system and the stratiform region which spread to the north direction. The echo system represents one of the MCSs (e.g., Zipser, 1982). Although negative CG occurred near the convective core region during the tornado generation, no CG was observed in the core region after the tornado. Most of the negative CG were observed around a relatively strong echo area in the stratiform region. The relatively strong echo area in the stratiform region was corresponding to the second peak of the MCS. A few positive CG lightning discharges were observed also in the stratiform region. The feature of the CG distribution was similar to that of the squall line with trailing stratiform region observed over Kansas (Rutledge and MacGorman, 1988). However, CG lightning activity was lower in the convective core region of the MCS compared to that of MCSs in the USA.

Figure 7 shows the temporal change of the radar echo area larger than $1 \mathrm{~mm} / \mathrm{h}$ and 40 $\mathrm{mm} / \mathrm{h}$ from 11:10 to 14:00 JST. The echo area was approximately $1000 \mathrm{~km}^{2}$ until 12:00 JST. The echo area increased after 12:00 JST and reached $4000 \mathrm{~km}^{2}$ at 14:00 JST. The area of the convective core region (stronger than $40 \mathrm{~mm} / \mathrm{h}$ ) increased from 11:30 JST. According to the change of the echo area, the developing stage was defined as the period when the convective core area increased. The mature stage was defined as the period when the convective area was fixed at the peak value and the decaying stage was the decreasing of the convective area. As a result, the evolution of the system was divided into three stages; the developing stage (11:00-12:20 JST), the mature stage (12:20-13:00 JST) and the decaying stage (13:00-14:00 JST), respectively. So, the Saroma tornado occurred at the decaying stage of the system (13:20 JST). Although the area of the convective core region decreased during the decaying stage, total area $(>1 \mathrm{~mm} / \mathrm{h})$ continued to increase.

Figure 8 shows 10-minutes CG frequency within the echo system as shown in Fig. 6 . Frequency of $\mathrm{CG}$ lightning in the system was inactive during the developing stage (11:00-12:00 JST). CG lightning exceeded 50 times at 12:10 JST. After 13:00 JST, CG lightning increased and the peak value (over 60 times) was observed at 13:30 JST (13:20 13:30) during the tornado generation. The rate of CG frequency exceeded 300 times per hour in the decaying stage. There were two peaks of CG activity; the first peak of CG was observed at 12:10 JST when the echo area of the convective core began to increase. In MCSs on the Great Plains of the USA, ground flash rates tend to increase as the area of the convective region increases (e.g., Kinzer, 1974). The second peak was appeared at 13:30 JST during the decaying stage and most of CG were observed in the stratiform region. Positive CG was approximately $10 \%$ of total CG during three hours and no positive CG was observed at both peaks (12:10 and 13:30 JST). 


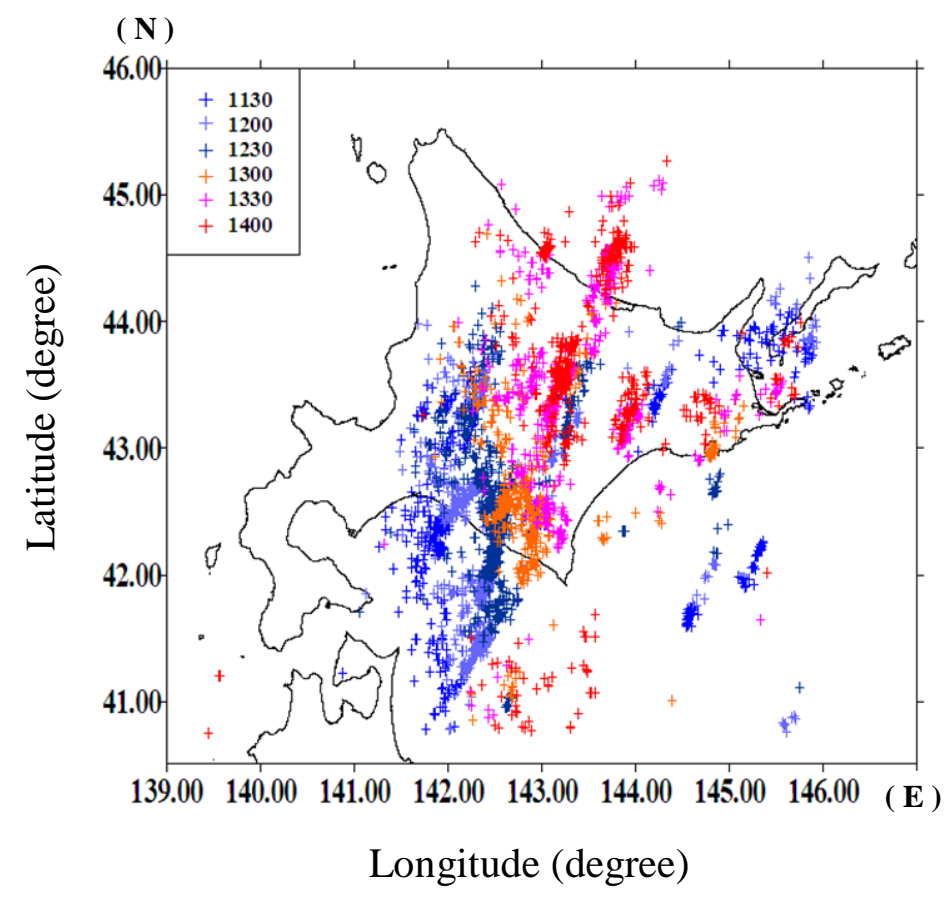

Fig. 4 CG lightning distribution from 11:30 to 14:00 JST on 7 November 2006 detected by LPATS and IMPACT systems. Color plus marks denote CG lightning during previous 30 minutes.

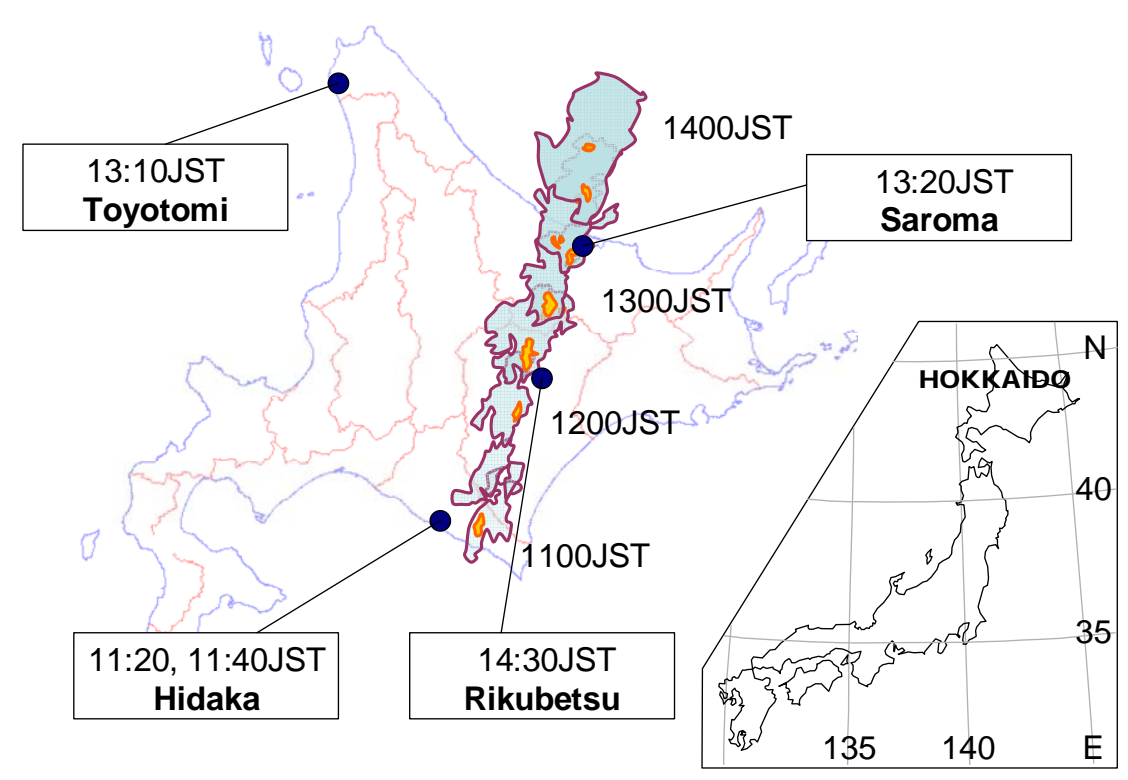

Fig. 5 Temporal change of the radar echo which caused Saroma tornado. Shaded (blue) area and dark (orange) area denote the radar intensity larger than $1 \mathrm{~mm} / \mathrm{h}$ and $40 \mathrm{~mm} / \mathrm{h}$, respectively. Solid circles denote the location of tornadic damage on the same day. 

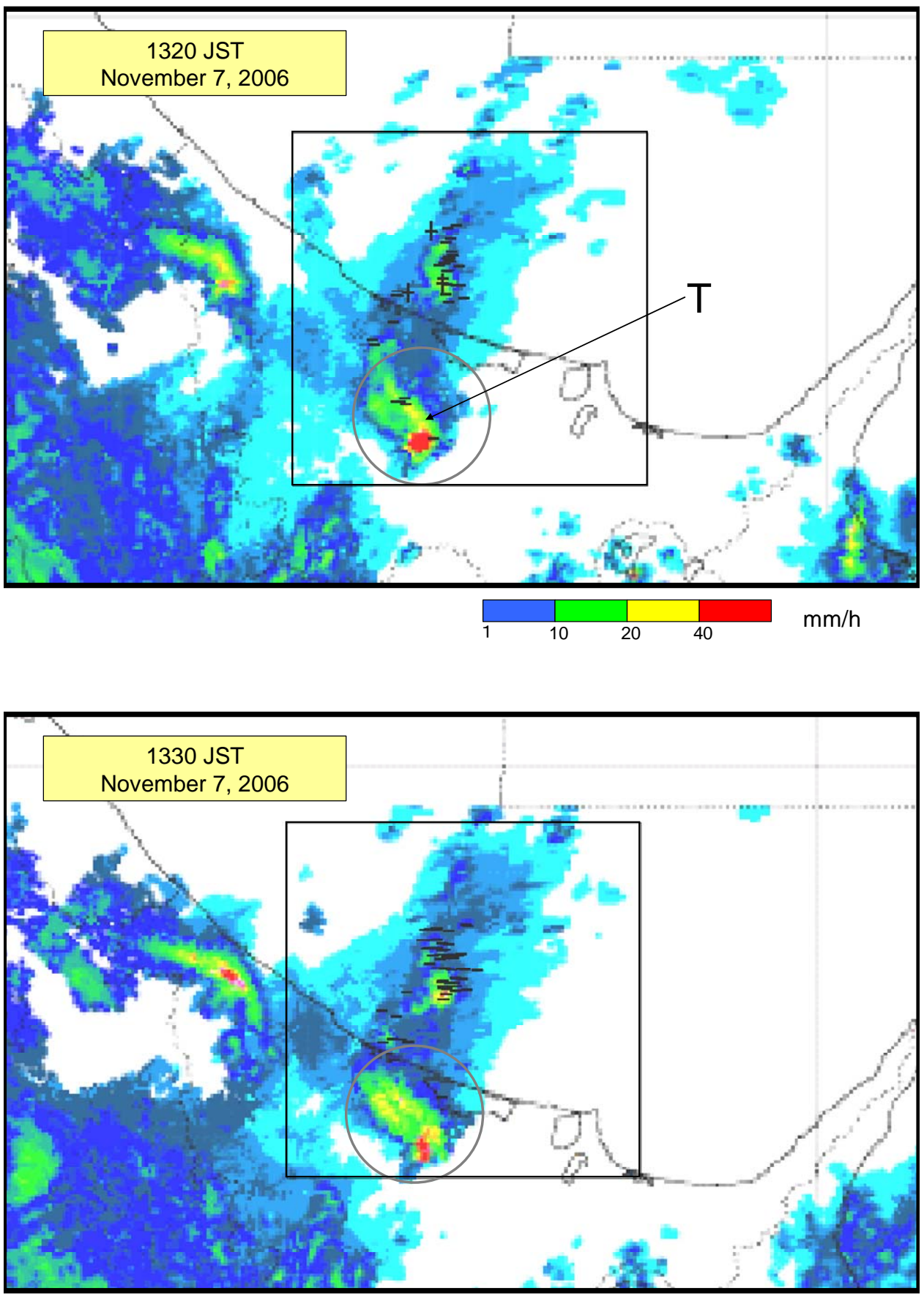

Fig. 6 JMA radar image at 13:20 (top) and 13:30 JST (bottom) superimposed by distribution of CG lightning during previous 10 minutes. Plus and minus marks denote positive and negative CG lightning, respectively. A rectangular region denotes the analyzed field of the radar echo area (Fig. 7) and CG frequency (Fig. 8). T (arrow) denotes the location of the Saroma tornado. 


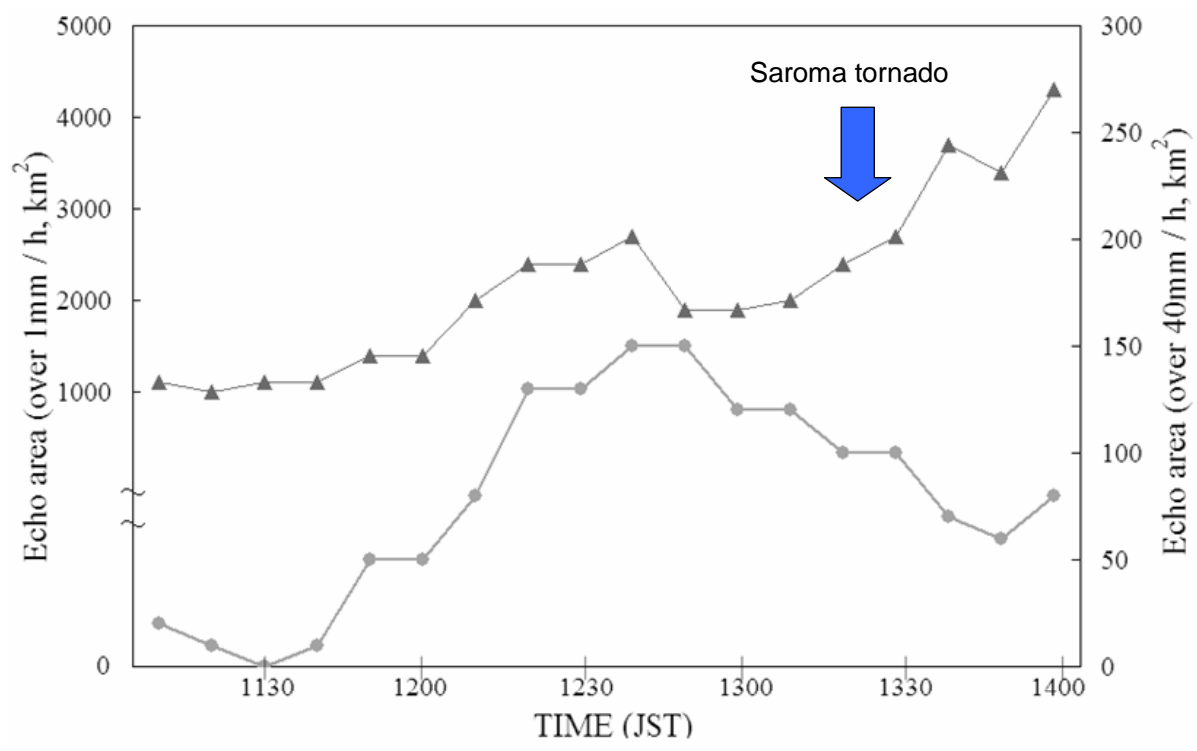

Fig. 7 Temporal change of the radar echo area from 11:10 to 14:00 JST. Triangle and circle denote the echo area larger than $1 \mathrm{~mm} / \mathrm{h}$ and $40 \mathrm{~mm} / \mathrm{h}$, respectively.

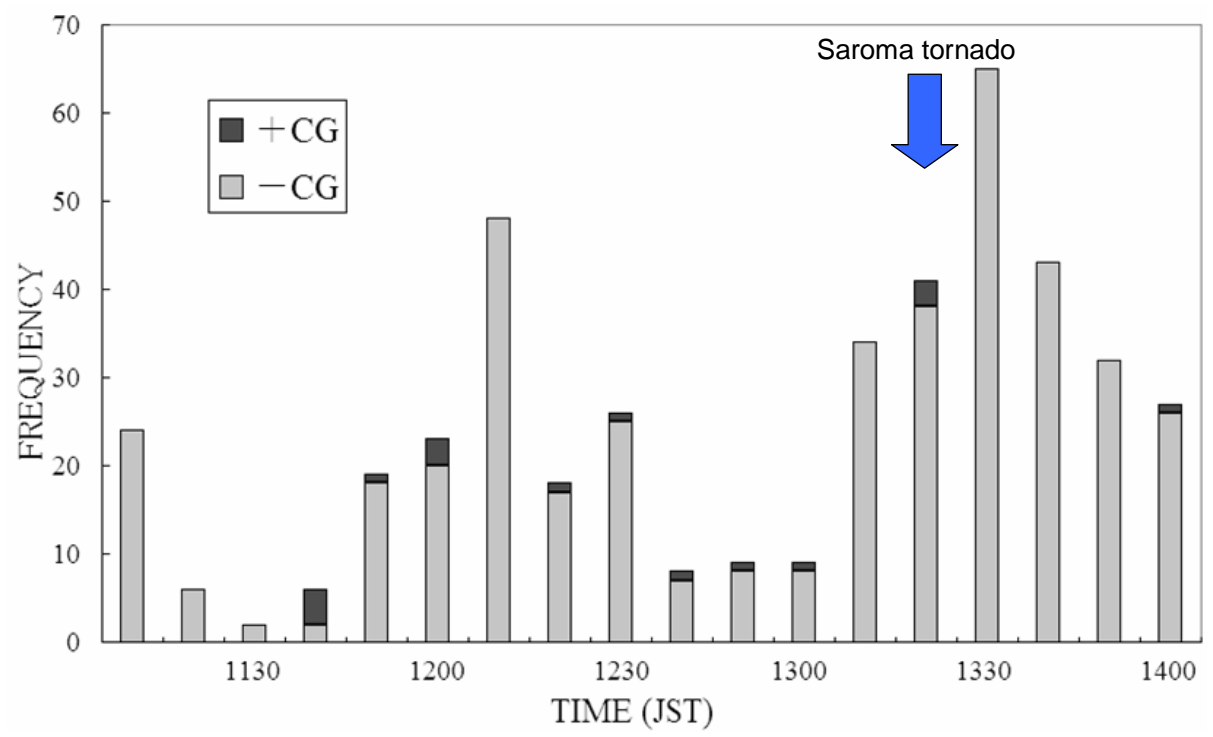

Fig. 8 Frequency of CG lightning during previous 10 minutes from 11:10 to 14:00 JST. 


\section{Discussion}

In the present case, Saroma tornado was corresponded to the time of CG lightning peak in the MCS. MacGorman and Nielsen (1991) showed the cases that ground flash rate peaked during tornadoes. Figure 9 shows temporal change of the CG flash rate per minute in the convective echo region from 12:50 to 14:00 JST. Hail precipitation was observed at the south side of the tornado place which is the same as the strongest convective core region (larger than $40 \mathrm{~mm} / \mathrm{h}$, red area in Fig. 6). The passage of a gustfront was observed at 13:20 JST around the generation point of the tornado and the tornado (No.1) touched down at 13:23 JST. The CG flash rate reached up to 4 times per minute during this period. Positive CG record at 13:20 JST (Fig. 8) implied that positive CG lightning was from the pocket positive region with hail precipitation around Saroma-cho.

In Saroma-cho, at approximately 13:20 JST on 7 November 2006, there were many eyewitness accounts of funnel clouds below the rotating cloud and the rotating wind of a "dust column" near the surface. The evidence of multiple suction vortices was also observed from the ground survey as shown in Fig. 2. The Saroma tornado was thought to be a mesocyclone related supercell tornado and three suction vortices (funnels) caused surface damage. On the other hand, the echo system was long-lasting (more than 3 hours) and had the features of the MCS both with the convective core region and the stratiform region (Fig. 6). Kato and Niino (2007) simulated the supercell type thunderstorm which brought the Saroma tornado and demonstrated that the simulated cloud system had a long-lasting mesocyclone and generated a tornado in Saroma-cho.

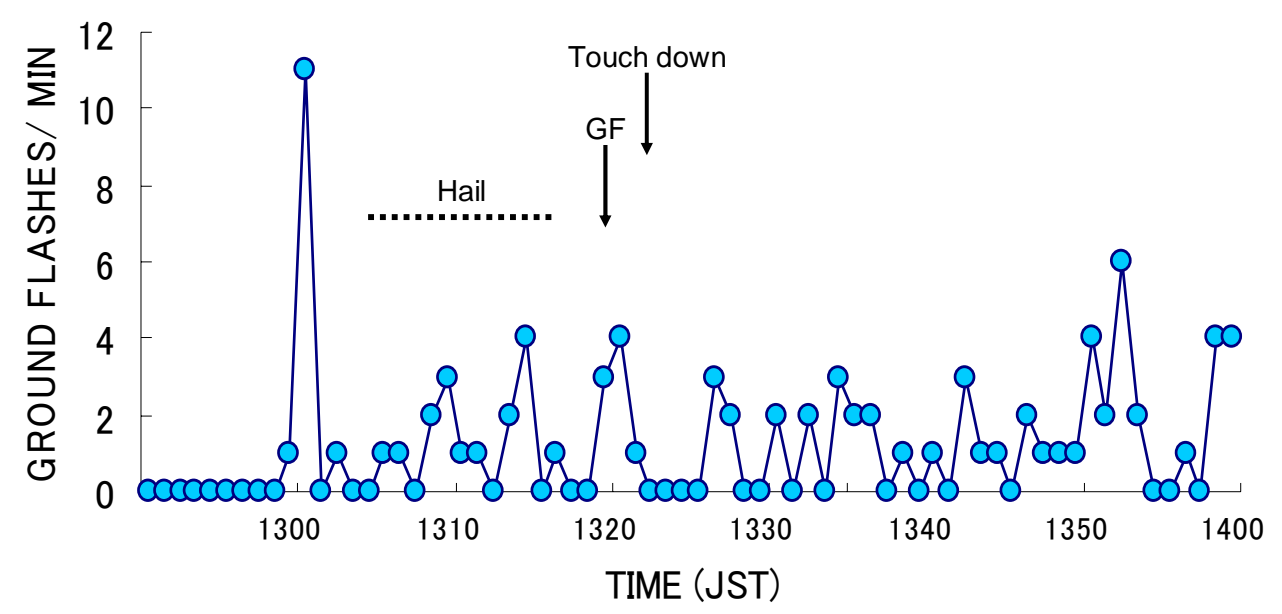

Fig. 9 Temporal change of the CG flash rate per minute in the convective core region from 12:50 to 14:00 JST. GF and touch down denote the passage of gustfront at Saroma-cho and the touch down of the tornado, respectively. 
In this case, other tornadic damage was reported in Hidaka-city at 11:20 and 11:40 JST (Fig. 5). It is assumed that the other tornadoes occurred around the echo system during the developing stage. The increase of the convective core (11:30 JST, in Fig.7) implied that a strong updraft was generated in the system. So, the echo system may have spawned tornadoes in the developing stage when the echo core was generated with few CG lightning. On the other hand, the Saroma tornado occurred in the decaying stage when the stratiform region increased with the $\mathrm{CG}$ peak.

Table 1 summarizes the list of major tornado events in Japan. The common features of the severe tornado of Japan were short lifetime ( 10 minutes), small scale and high moving speed except for the Toyohashi tornado. Many non-supercell type tornadoes occurred in Japan, which have only misocyclones in the parent cloud. Generally, misocyclones have smaller scale in diameter and short lifetime compared to mesocyclones in supercell type thunderstorms (e.g., Kobayashi et al. 1996). So, it is difficult to monitor non-supercell type tornadoes by a Doppler radar. It is thought that CG lightning data may be good information for the nowcasting small tornadic storms. Further studies are needed to accumulate data on the CG activity and distribution around tornado-related thunderstorms. Moreover, intensive observations are needed to understand the fine structure of tornadic storms using Doppler radars and LLS systems in Japan.

Table 1 List of the major tornado damages in Japan.

\begin{tabular}{|l|c|c|c|c|c|}
\hline $\begin{array}{l}\text { tornado } \\
\text { event }\end{array}$ & $\begin{array}{c}\text { Mobara } \\
1990.12 .11\end{array}$ & $\begin{array}{c}\text { Toyohashi } \\
1999.09 .24\end{array}$ & $\begin{array}{c}\text { Saga } \\
2004.06 .27\end{array}$ & $\begin{array}{c}\text { Nobeoka } \\
2006.09 .18\end{array}$ & $\begin{array}{c}\text { Saroma } \\
2006.11 .07\end{array}$ \\
\hline $\begin{array}{l}\text { Life time } \\
\text { (min) }\end{array}$ & 7 & 25 & 7 & 5 & 3 \\
\hline F scale & $\mathrm{F} 3$ & $\mathrm{~F} 3$ & $\mathrm{~F} 2$ & $\mathrm{~F} 2$ & $\mathrm{~F} 3$ \\
\hline $\begin{array}{l}\text { P scale } \\
\text { (length) }\end{array}$ & $\begin{array}{c}\mathrm{P} 2 \\
6.5 \mathrm{~km}\end{array}$ & $\begin{array}{c}\mathrm{P} 3 \\
19 \mathrm{~km}\end{array}$ & $\begin{array}{c}\mathrm{P} 2 \\
8 \mathrm{~km}\end{array}$ & $\begin{array}{c}\mathrm{P} 2 \\
7.5 \mathrm{~km}\end{array}$ & $\begin{array}{c}\mathrm{P} 1 \\
1.5 \mathrm{~km}\end{array}$ \\
\hline $\begin{array}{l}\text { P scale } \\
\text { width) }\end{array}$ & $\mathrm{P} 3$ & $\mathrm{P} 3$ & $\mathrm{P} 2$ & $\mathrm{P} 2$ & $\mathrm{P} 2$ \\
$200 \mathrm{~m}$ & $550 \mathrm{~m}$ & $200 \mathrm{~m}$ & $250 \mathrm{~m}$ & $300 \mathrm{~m}$ \\
\hline $\begin{array}{l}\text { Moving } \\
\text { speed (m/s) }\end{array}$ & 16 & 13 & 18 & 25 & 20 \\
\hline $\begin{array}{l}\text { Number of } \\
\text { damage }\end{array}$ & 1800 & 2500 & 500 & 1400 & 100 \\
\hline $\begin{array}{l}\text { Synoptic } \\
\text { situation }\end{array}$ & Low & Typhoon & $\begin{array}{l}\text { Stationary } \\
\text { Front }\end{array}$ & Typhoon & Cold front \\
\hline
\end{tabular}

F scale : FO(17-32), F1(33-49), F2(50-69), F3(70-92 m/s)

$P$ scale (length) : P1(1.6-5), P2(5-15), P3(16-49 km)

P scale (width) : P1(16-50), P2(51-160), P3(161-499 m) 


\section{Conclusions}

The relationship between the evolution of the tornadic storm and the CG activity was investigated on the F3 tornado event in Saroma-cho, Hokkaido on 7 November 2006. The features of the MCS which caused the tornado and the corresponding CG lightning were presented. Conclusions of this study are as follows:

(1) The echo system which caused tornadoes in Saroma-cho was the MCS having both the convective core region and the stratiform region. The system was long-lasting (> 3 hours) and the Saroma tornado occurred at the decaying stage of the system.

(2) CG lightning of the MCS was active in the decaying stage. Most CG lightning was negative and occurred around a relatively strong echo area in the stratiform region.

(3) The MCS had two peaks of the CG lightning at the developing stage and the decaying stage. The Saroma tornado occurred at the decaying stage when the concentration of CG frequency (over 60 times per 10 minutes) was observed.

\section{Acknowledgments}

The authors wish to offer great thanks to the members who surveyed the tornado: Dr. S. Cao (Tokyo Polytechnic University), Dr. A. Yoshida (Tokyo Polytechnic University), and Dr. H. Kikuchi (Shimizu Research Institute). The authors would also like to thank the Japan Meteorological Agency (JMA) and Franklin Japan Corporation for providing the meteorological data and the lightning data. This observational study was supported by the 21st COE Program: Wind Effects on Buildings and Urban Environment of the Tokyo Polytechnic University.

\section{References}

Fujita, T. T., Tornadoes and downbursts in the context of generalized planetary scales, $J$. Atmos. Sci., 38, 1511-1534, 1981.

Kane, R. J., Correlating lightning to severe local storms in the northeastern United States, Wea. Forecasting, 6, 3-12, 1991.

Kato, T. and H. Niino, Environment of the tornado observed in Saroma-cho, Hokkaido on 7 November 2006, Proceedings of the Meteorological Society of Japan (spring meeting), 92, 2007 (in Japanese).

Kinzer, G. D., Cloud-to-ground lightning versus radar reflectivity in Oklahoma thunderstorms, J.Atmos. Sci., 31, 787-799, 1974.

Kobayashi, F., Structures of a thundercloud occurred in Yamagata prefecture on 25 December 2005, Proceedings of the Society of Atmospheric Electricity of Japan, 69, 59-60, 2006 (in Japanese).

Kobayashi, F., Structures of tornadoes and gustfronts observed by a Doppler radar, Proceedings of International Conference on X-band Radar Network, Tsukuba, 37-42, 2007.

Kobayashi, F., K. Kikuchi and H. Uyeda, Life cycle of the Chitose tornado of September 22, 1988, J. Meteor. Soc. Japan, 74, 125-140, 1996.

Kobayashi, F., Y. Sugawara, M. Imai, M. Matsui, A. Yoshida and Y. Tamura, Tornado generation in a narrow cold frontal rainband -Fujisawa tornado on April 20, 2006, SOLA, 3, 21-24, 2007a. 
Kobayashi, F., Y. Sugimoto, T. Suzuki, T. Maesaka and Q. Moteki, Doppler radar observation of a tornado generated over the Japan Sea coast during a cold air outbreak, J. Meteor. Soc. Japan, 85, 321-334, 2007b.

MacGorman, D. R. and K. E. Nielsen, Cloud-to-ground lightning in a tornadic storm on 8 May 1986, Mon. Wea. Rev., 119, 1557-1574, 1991.

Niino, H., O. Suzuki, H. Nirasawa, T. Fujitani, H. Ohno, I. Takayabu, N. Kinoshita and Y. Ogura, Tornadoes in Chiba Prefecture on 11 December 1990, Mon. Wea. Rev., 121, 3001-3018, 1993.

Orville, R. E., M. W. Maier, F. R. Mosher, D. P. Wylie and W. D. Rust, The simultaneous display in a severe storm of lightning ground strike location onto satellite images and radar reflectivity patterns, Preprints 12th Conf. Severe Local Storms, Amer. Meteor. Soc., 448-451, 1982.

Rutledge, S. A. and D. R. MacGorman, Cloud-to-ground lightning activity in the 10-11 June 1985 convective system observed during the Oklahoma-Kansas PRE-STORM project, Mon. Wea. Rev., 116, 1393-1408, 1988.

Rutledge, S. A., C. Lu and D. R. MacGorman, Positive cloud-to-ground lightning flashes in mesoscale convective systems, J. Atmos. Sci., 47, 2085-2100, 1990.

Sugawara, Y. and F. Kobayashi, Structure of a waterspout occurred over Tokyo Bay on May 31, 2007, SOLA, 4, 1-4, 2008.

Zipser, E. J., Nowcasting, K. A. Browning, ed., Academic press, London, 191-204, 1982.

(Received August 26, 2008; revised September 30, 2008; accepted October 1, 2008) 